\title{
Improvement of the thermal stability of dendritic silver-coated copper microparticles by surface modification based on molecular self-assembly
}

\author{
Tae Hyeong Kim ${ }^{1 \dagger}$, Hyeji $\mathrm{Kim}^{2 \dagger}$, Hyo Jun Jang ${ }^{2}$, Nara Lee ${ }^{1}$, Kwang Hyun Nam³ ${ }^{3}$ Dae-won Chung ${ }^{2 *}$ and
} Seunghyun Lee ${ }^{45^{*}}$ (1)

\begin{abstract}
In the study reported herein, silver-coated copper $(\mathrm{Ag} / \mathrm{Cu})$ powder was modified with alkanethiols featuring alkyl chains of different lengths, namely butyl, octyl, and dodecyl, to improve its thermal stability. The modification of the $\mathrm{Ag} / \mathrm{Cu}$ powders with adsorbed alkanethiols was confirmed by scanning electron microscopy with energy dispersive spectroscopy, X-ray photoelectron spectroscopy, and thermogravimetric analysis. Each powder was combined with an epoxy resin to prepare an electrically conductive film. The results confirmed that the thermal stability of the films containing alkanethiol-modified $\mathrm{Ag} / \mathrm{Cu}$ powders is superior to that of the film containing untreated $\mathrm{Ag} / \mathrm{Cu}$ powder. The longer the alkyl group in the alkanethiol-modified Ag/Cu powder, the higher the initial resistance of the corresponding electrically conductive film and the lower the increase in resistance induced by heat treatment.
\end{abstract}

Keywords: Ag/Cu, Alkanethiol, Conductive film, Thermal stability

\section{Introduction}

Electrically conductive adhesives are widely used in the fabrication of electronic devices and mechanical attachments, and generally consist of a polymer matrix and conductive metal fillers. The purpose and application range of electrically conductive adhesives have expanded dramatically over time and various materials, such as metals (including $\mathrm{Au}, \mathrm{Ag}, \mathrm{Al}$, and $\mathrm{Cu}[1,2]$ ), carbon fibers [3], and graphite $[4,5]$ have been employed as fillers. While noble metals are chemically stable and demonstrate excellent electrical and thermal properties, $\mathrm{Cu}$ and $\mathrm{Ni}$ are researched and applied more extensively than

\footnotetext{
*Correspondence: dwchung@suwon.ac.kr; leeshyun@hanyang.ac.kr †Tae Hyeong Kim and Hyeji Kim contributed equally to this work ${ }^{2}$ Department of Polymer Engineering, College of Engineering, University of Suwon, Suwon 18323, Republic of Korea

${ }^{4}$ Department of Chemical and Molecular Engineering, Hanyang University, Ansan-Si 15588, Republic of Korea

Full list of author information is available at the end of the article
}

noble metals owing to their greater affordability. However, $\mathrm{Cu}$ is more widely used than $\mathrm{Ni}$, despite its vulnerability to oxidation, since the electrical properties of $\mathrm{Ni}$ are inferior to those of $\mathrm{Cu}$. Multiple studies have explored strategies to prevent or inhibit the corrosion of $\mathrm{Cu}$ in the presence of oxygen. Strategies that have been developed to prevent the oxidation of $\mathrm{Cu}$, including the employment of protective azole compounds [6, 7], amines [8], and self-assembling thiol compounds [9], are well organized in a published review [10].

Ag-coated $\mathrm{Cu}(\mathrm{Ag} / \mathrm{Cu})$ conductive metal powders are commonly used in industry and while various methods exist to produce these Ag-coated $\mathrm{Cu}$ powders [11, $12]$, related technologies are typically protected by patents [13-16]. The vulnerability of $\mathrm{Ag} / \mathrm{Cu}$ powders to oxidation depends on their Ag content. For example, the electrical performance of an electrically conductive, epoxy-based adhesive containing $20 \mathrm{vol} \% \mathrm{Ag} / \mathrm{Cu}$ powder with a Ag content of $15 \%$ remains relatively steady 
for approximately $2 \mathrm{~h}$ at $200{ }^{\circ} \mathrm{C}$, however, its resistance increases rapidly above $250{ }^{\circ} \mathrm{C}$ [17]. In contrast, the resistance of an adhesive containing non-coated $\mathrm{Cu}$ powder increases significantly at a mere $100{ }^{\circ} \mathrm{C}$. Studies have revealed that the electrical properties of a $\mathrm{Cu}$-containing electrically conductive adhesive change under pressure [18] and the distribution of Ag on the surface of Ag-coated $\mathrm{Cu}$ particles, determined by the Ag content and coating process, directly affects the degree of oxidation observed [19]. Ag/Cu powders are widely applied in electrically conductive adhesives and it is possible to fabricate $\mathrm{Ag} / \mathrm{Cu}$ powders with different shapes through various manufacturing methods [12, 20-22]. It is well known that spherical $\mathrm{Ag} / \mathrm{Cu}$ powder particles are suitable for anisotropic conductive adhesives, and $\mathrm{Ag} / \mathrm{Cu}$ flakes are suitable for isotropic conductive adhesives [23, $24]$. It has also been reported that $\mathrm{Ag} / \mathrm{Cu}$ powders treated with silane coupling agents show more reliable electrical properties [24]. These research results have informed the analytical and chemical study of the behavior of $\mathrm{Ag} / \mathrm{Cu}$ powder in epoxy-based adhesives [25].

In this study, the surfaces of dendritic $\mathrm{Ag} / \mathrm{Cu}$ powders were modified with self-assembling alkanethiols. These modified surfaces were analyzed by scanning electron microscopy with energy dispersive X-ray spectroscopy (SEM-EDS), X-ray photoelectron spectroscopy (XPS), and thermogravimetric analysis (TGA). In addition, epoxy-based composite films containing the $\mathrm{Ag} / \mathrm{Cu}$ powders modified with alkanethiols featuring different alkylchain lengths were prepared to investigate their thermal stability and electrical resistance.

\section{Experimental}

\subsection{Chemicals}

The alkanethiols (butanethiol, octanethiol, and dodecanethiol) used to modify the surfaces of $\mathrm{Ag} / \mathrm{Cu}$ powders were purchased from Sigma-Aldrich. Ag/Cu powder dispersed in isopropyl alcohol (IPA), without surface treatment after Ag coating, was supplied by JC Metal (Korea). The epoxy resin (YDPN 644, epoxy equivalent weight $=195-235 \mathrm{~g} / \mathrm{eq}$ ) and curing agent, phthalic anhydride (MNA), employed in the preparation of electrically conductive films were supplied by Kukdo Chemical (Korea). Toluene (99.5\%, Daejung Chemical, Korea) served as a diluent. All chemicals were used as received, without purification.

\subsection{Surface modification of $\mathrm{Ag} / \mathrm{Cu}$ powders}

To prepare octanethiol-modified $\mathrm{Ag} / \mathrm{Cu}\left(\mathrm{Ag} / \mathrm{Cu}-\mathrm{C}_{8}\right)$ powder, $1 \mathrm{~g}$ of $\mathrm{Ag} / \mathrm{Cu}$ powder was placed in a conical tube and dispersed in $30 \mathrm{ml}$ of anhydrous ethanol using a vortex mixer. After centrifuging the mixture at $6000 \mathrm{rpm}$ for $10 \mathrm{~min}$, the supernatant was decanted and the precipitate was washed with anhydrous ethanol. The procedure was repeated three times. Next, $40 \mathrm{~mL}$ of an ethanol solution containing octanethiol $(50 \mathrm{mM})$ was added to the conical tube and dispersed well using a vortex mixer for a few tens of seconds. The reagents were allowed to react while mixing in a vertical rotary tube mixer (IKA Trayster Rotator, $50 \mathrm{rpm}$ ) for $24 \mathrm{~h}$. After thorough dispersion using an ultrasonicator and a vortex mixer, centrifugation was performed 5 times (each time the mixture was centrifuged at $6000 \mathrm{rpm}$ for $10 \mathrm{~min}$ and the supernatant decanted before the addition of $40 \mathrm{~mL}$ anhydrous ethanol) to remove unreacted octanethiol. Finally, the precipitate was vacuum dried at $40{ }^{\circ} \mathrm{C}$ to obtain the modified $\mathrm{Ag} / \mathrm{Cu}$ powder. Butanethiol and dodecanethiol were reacted with $\mathrm{Ag} / \mathrm{Cu}$ powder to prepare $\mathrm{Ag} / \mathrm{Cu}-\mathrm{C}_{4}$ and $\mathrm{Ag} / \mathrm{Cu}-\mathrm{C}_{12}$ powders, respectively, using the same surface modification procedure.

\subsection{Preparation and evaluation of electrically conductive films}

Each modified $\mathrm{Ag} / \mathrm{Cu}$ powder (6.2 g) was mixed with epoxy resin (2 g), curing agent, and toluene (5 g), and stirred at $500 \mathrm{rpm}$ for $2 \mathrm{~min}$. Each mixture was defoamed for 3 min under vacuum to prepare a conductive paste that was repeatedly applied (10 times) onto a polyimide film using a Mayer rod coater (wet film thickness of $22.9 \mu \mathrm{m})$ and dried at $100{ }^{\circ} \mathrm{C}$ for $2 \mathrm{~min}$. The prepared films were cured at $160{ }^{\circ} \mathrm{C}$ for $1 \mathrm{~h}$, and cut to an appropriate size $(7 \mathrm{~cm} \times 1 \mathrm{~cm})$. The surface roughness at five points on each film (the center point was $1 \mathrm{~cm}$ from the top) was measured to obtain the average value and standard deviation. The thermal properties of the conductive films were examined using two methods. As a simple test, the change in the linear resistance of each electrically conductive film over a length of $5 \mathrm{~cm}$ was measured in an oven at $180{ }^{\circ} \mathrm{C}$ over time. The conductive films were cured and laminated on a test circuit coupon at $160{ }^{\circ} \mathrm{C}$ under a pressure of $10 \mathrm{kgf} / \mathrm{cm}^{2}$ for $1 \mathrm{~h}$. The initial linear resistance of each film was measured over a distance of $5 \mathrm{~cm}$ before the specimens were placed in a solder pot at $260{ }^{\circ} \mathrm{C}$ for $10 \mathrm{~s}$. After cooling at $25{ }^{\circ} \mathrm{C}$ for $10 \mathrm{~min}$, the linear resistance was again measured over a distance of $5 \mathrm{~cm}$. This heat treatment and linear resistance measurement process was repeated three times.

\subsection{Characterization of alkanethiol-modified $\mathrm{Ag} / \mathrm{Cu}$ powder surfaces}

The morphological and chemical analyses of the modified $\mathrm{Ag} / \mathrm{Cu}$ powders were performed by SEM-EDS (Apreo, FEI), XPS (K-Alpha, Thermo Fisher Scientific), and TGA (TGA 4000, Perkin Elmer). The TGA was carried out under a nitrogen atmosphere (nitrogen flow rate: $50 \mathrm{~mL} /$ $\mathrm{min}$ ) while the temperature was increased from room 
temperature to $600{ }^{\circ} \mathrm{C}$ at a rate of $10{ }^{\circ} \mathrm{C} / \mathrm{min}$. To evaluate the oxidation behavior of the $\mathrm{Ag} / \mathrm{Cu}$ particles, TGA was performed under the same conditions as above without nitrogen injection. The surface roughness values (arithmetic mean roughness ( $\mathrm{Ra})$, ten-point mean roughness $(\mathrm{Rz}))$ of the films were measured to investigate the dispersion of the $\mathrm{Ag} / \mathrm{Cu}$ particles in the epoxy resin using a surface roughness tester (Mitutoyo Surftest, Japan).

\section{Results and discussion}

\subsection{Alkanethiol modification of $\mathrm{Ag} / \mathrm{Cu}$ surfaces and their characterization}

The alkanethiol modification of the $\mathrm{Ag} / \mathrm{Cu}$ powder particle surfaces in this study is similar to a previously reported method of $\mathrm{Cu}$ particle surface modification through self-assembling thiol compounds [9]. The surface morphology of the modified $\mathrm{Ag} / \mathrm{Cu}$ powder particles was investigated by SEM. Figure 1 shows SEM images of dendritic $\mathrm{Ag} / \mathrm{Cu}$ powder particles that are untreated and modified with different alkanethiols, respectively. The $\mathrm{Ag} / \mathrm{Cu}$ powder particle in Fig. 1a has various dendritic protrusions on its surface and its major axis is approximately 15-20 $\mu \mathrm{m}$ long. The alkanethiol-modified $\mathrm{Ag} / \mathrm{Cu}$ powder particles do not differ significantly in shape or size from the untreated $\mathrm{Ag} / \mathrm{Cu}$ powder particle. The surfaces of the protrusions on the alkanethiol-modified $\mathrm{Ag} /$ $\mathrm{Cu}$ powder particles seem slightly less rough than those of the protrusions of the untreated $\mathrm{Ag} / \mathrm{Cu}$ powder particle, however, it is difficult to confirm the surface modification through SEM alone. Therefore, EDS and XPS analyses were performed to compare the relative constituent element contents based on the chemical compositions of the surface-modified $\mathrm{Ag} / \mathrm{Cu}$ powder particles; the results are summarized in Table 1.

The EDS data in Table 1 show that the $\mathrm{S}$ content of the untreated $\mathrm{Ag} / \mathrm{Cu}$ powder (relative to its $\mathrm{Ag}(\mathrm{S} / \mathrm{Ag}$ ) and $\mathrm{C}(\mathrm{S} / \mathrm{C})$ contents) is negligible; unlike the relative $\mathrm{S}$ contents of the alkanethiol-modified $\mathrm{Ag} / \mathrm{Cu}$ powders. A similar trend is observed in the relative $\mathrm{C}(\mathrm{C} / \mathrm{Ag})$ contents of the untreated and alkanethiol-modified $\mathrm{Ag} / \mathrm{Cu}$ powders, confirming that the surfaces of the treated $\mathrm{Ag} / \mathrm{Cu}$ powders are modified by alkanethiol compounds.

The $\mathrm{C}$ content of the alkanethiol-modified $\mathrm{Ag} / \mathrm{Cu}$ powders (relative to their $\mathrm{Ag}(\mathrm{C} / \mathrm{Ag})$ content) increases with increasing alkyl-chain length, whereas their relative $\mathrm{S}$ content decreases with increasing alkyl-chain length. These observations are explained by the structures of the alkanethiols, i.e., the longer the alkyl chain, the smaller

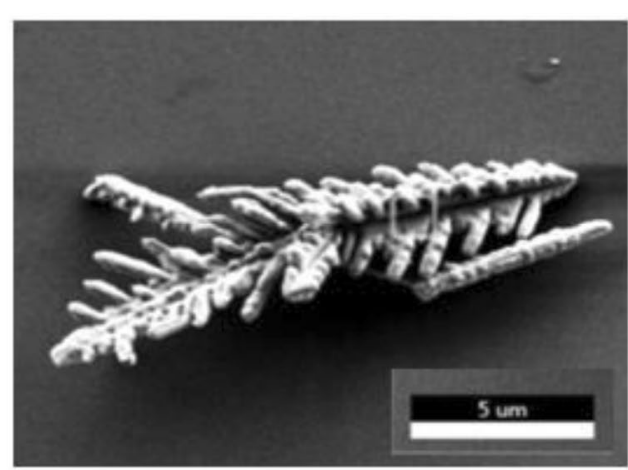

a

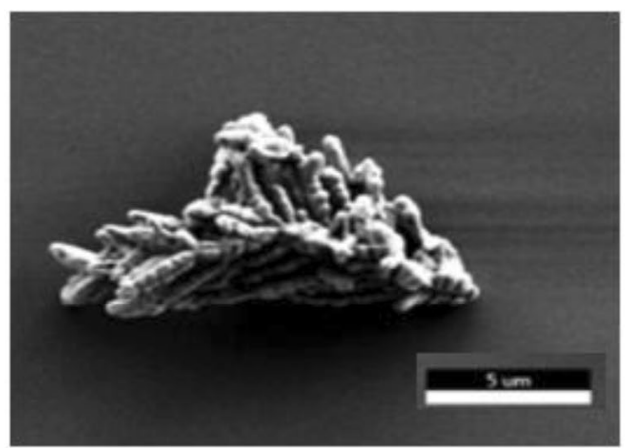

C

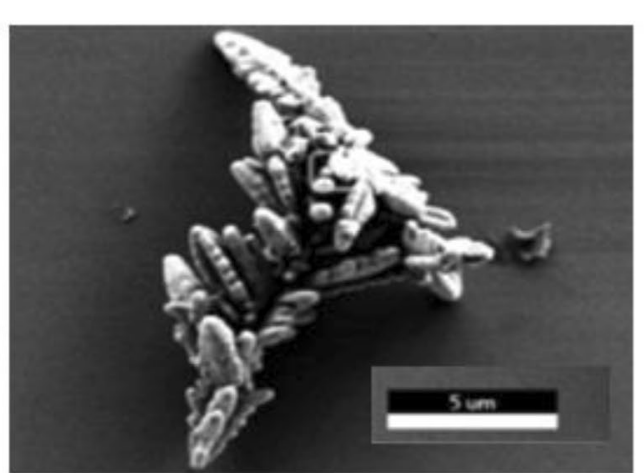

b

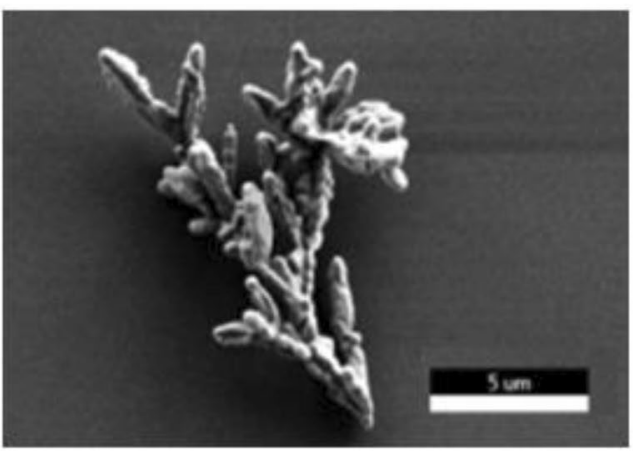

d

Fig. 1 SEM images of a untreated $\mathrm{Ag} / \mathrm{Cu}, \mathbf{b} \mathrm{Ag} / \mathrm{Cu}-\mathrm{C}_{4}, \mathbf{c} \mathrm{Ag} / \mathrm{Cu}-\mathrm{C}_{8}$, and $\mathbf{d} \mathrm{Ag} / \mathrm{Cu}-\mathrm{C}_{12}$ powder particles 
Table 1 Relative atomic contents (\%) of Ag/Cu and modified Ag/Cu particles measured by EDS and XPS

\begin{tabular}{|c|c|c|c|c|c|c|c|c|}
\hline & \multicolumn{4}{|c|}{ Relative atomic \% (EDS) } & \multicolumn{4}{|c|}{ Relative atomic \% (XPS) } \\
\hline & $\mathrm{Ag} / \mathrm{Cu}$ & $\mathrm{Ag} / \mathrm{Cu}-\mathrm{C}_{4}$ & $\mathrm{Ag} / \mathrm{Cu}-\mathrm{C}_{8}$ & $\mathrm{Ag} / \mathrm{Cu}-\mathrm{C}_{12}$ & $\mathrm{Ag} / \mathrm{Cu}$ & $\mathrm{Ag} / \mathrm{Cu}-\mathrm{C}_{4}$ & $\mathrm{Ag} / \mathrm{Cu}-\mathrm{C}_{8}$ & $\mathrm{Ag} / \mathrm{Cu}-\mathrm{C}_{12}$ \\
\hline $\mathrm{C} / \mathrm{Ag}$ & 1.89 & 5.51 & 5.97 & 5.29 & 1.25 & 6.25 & 7.34 & 8.16 \\
\hline $\mathrm{S} / \mathrm{Ag}$ & 0.01 & 0.31 & 0.14 & 0.08 & 0.04 & 1.12 & 0.83 & 0.73 \\
\hline$S / C$ & 0.00 & 0.06 & 0.02 & 0.01 & 0.03 & 0.16 & 0.13 & 0.09 \\
\hline
\end{tabular}
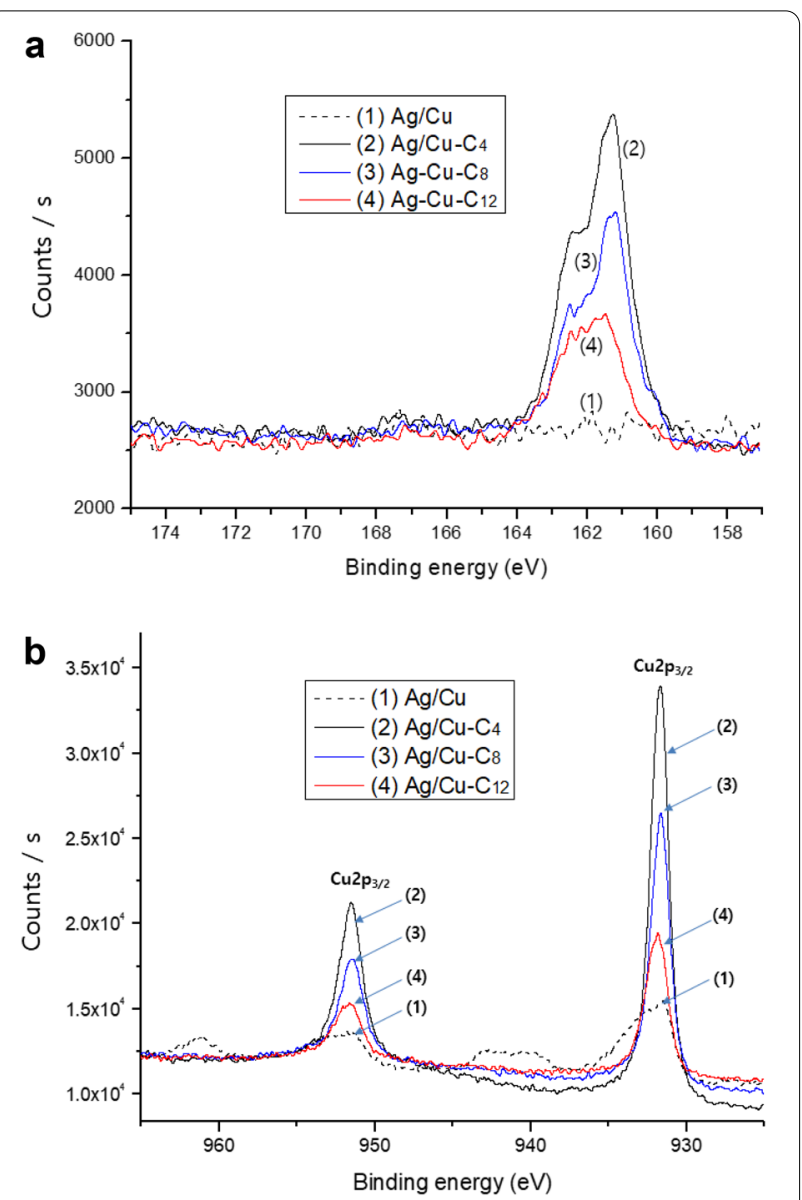

Fig. 2 High-resolution XPS spectra reflecting the $\mathbf{a}$ S2p and $\mathbf{b} \mathrm{Cu} 2 \mathrm{p}$ peaks of (1) Ag/Cu, (2) Ag/Cu-C $\mathrm{C}_{4}$ (3) $\mathrm{Ag} / \mathrm{Cu}-\mathrm{C}_{8}$, and (4) $\mathrm{Ag} / \mathrm{Cu}-\mathrm{C}_{12}$ powders

the atomic ratio of $S$ to $C$. The decreasing $S / C$ values reflected in Table 1 clearly illustrates this phenomenon. Furthermore, the trends observed in the results obtained by XPS are similar to those observed in the results obtained by EDS despite the fact that the results of the two analytical methods do not correspond quantitatively because they differ in principle. A comparison of the XPS spectra of the untreated and alkanethiol-modified $\mathrm{Ag} /$ $\mathrm{Cu}$ powders in Fig. 2a reveals that a S2p peak, indicating the presence of $S$, does not appear in the spectrum of the untreated $\mathrm{Ag} / \mathrm{Cu}$ powder, whereas S2p peaks at $161.8 \mathrm{eV}$ are observed in the spectra of the alkanethiol-modified $\mathrm{Ag} / \mathrm{Cu}$ powders. The intensity of the $\mathrm{S} 2 \mathrm{p}$ peak decreases with increasing alkyl-chain length of the alkanethiolmodified $\mathrm{Ag} / \mathrm{Cu}$ powders. The absolute areas under the various peaks in the spectra of the specimens cannot be quantitatively compared, but the results shown in Fig. 2 are consistent with the relative atomic contents summarized in Table 1. The XPS spectrum of the untreated Ag/ $\mathrm{Cu}$ powder (1) in Fig. 2b shows four typical peaks associated with partially oxidized $\mathrm{Cu}$ [26]. However, in the spectra of the alkanethiol-modified $\mathrm{Ag} / \mathrm{Cu}$ powders, only the $\mathrm{Cu} 2 \mathrm{p}_{3 / 2}$ and $\mathrm{Cu} 2 \mathrm{p}_{1 / 2}$ peaks at 931.8 and $952.5 \mathrm{eV}$ are observed, which suggest that the presence of $\mathrm{Cu}$ oxide is limited by the adsorbed alkanethiols on the $\mathrm{Ag} / \mathrm{Cu}$ particle surfaces. In fact, in another study of $\mathrm{Cu}$ particles modified with dodecanethiol, the simultaneous analysis of multi-element XPS spectra revealed peaks attributed to $\mathrm{Cu} 2 \mathrm{p}_{3 / 2}$ and $\mathrm{Cu} 2 \mathrm{p}_{1 / 2}$ at 931.9 and $952.2 \mathrm{eV}$, respectively [27]. The relative constituent element contents of the alkanethiol-treated and untreated $\mathrm{Ag} / \mathrm{Cu}$ powders determined by EDS and XPS suggest that the surfaces of the treated $\mathrm{Ag} / \mathrm{Cu}$ powders are well modified with alkanethiols, and the amount of $\mathrm{C}$ can be controlled by changing the alkyl-chain lengths of the alkanethiols. Moreover, the alkanethiols are well self-assembled on the surfaces of the treated $\mathrm{Ag} / \mathrm{Cu}$ powders based on the $\mathrm{S}$ and $\mathrm{Cu}$ peaks observed in their XPS spectra.

In general, when the surfaces of metals or inorganic materials are functionalized or modified with organic materials, TGA enables the measurement of the organic material content by monitoring the weight loss of a relevant sample as a function of temperature or time [28]. In this study, we evaluated the weight loss as a function of temperature under a nitrogen atmosphere. The TGA curves in Fig. 3 suggest that there is almost no change in the weight of the samples with increasing temperature and no significant difference is observed between the TGA curves of the untreated and alkanethiol-modified $\mathrm{Ag} / \mathrm{Cu}$ powders, even in the inset in Fig. 3 that magnifies the region of change.

The greatest difference between the maximum and minimum recorded weight percentages is approximately 


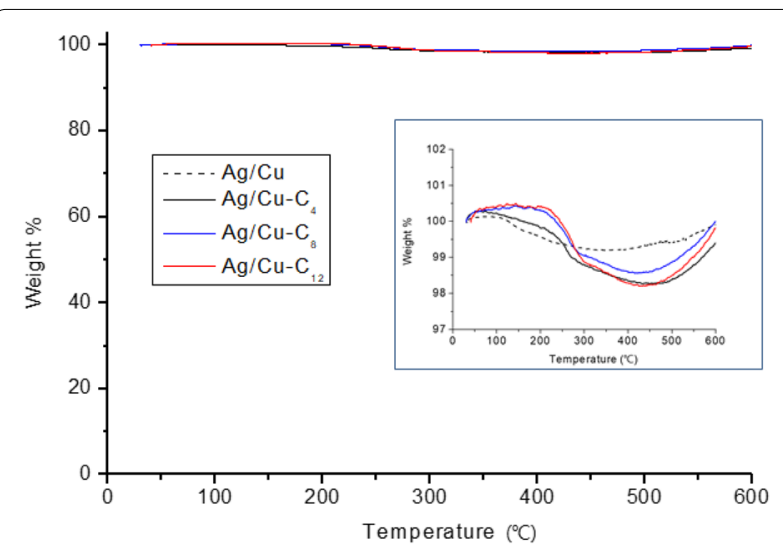

Fig. $3 \mathrm{TGA}$ of untreated $\mathrm{Ag} / \mathrm{Cu}$ and alkanethiol-modified $\mathrm{Ag} / \mathrm{Cu}$ powders under nitrogen atmosphere

$2 \mathrm{wt} \%$; therefore, it is reasonable to conclude that the content of the alkanethiols bound to the surfaces of the treated $\mathrm{Ag} / \mathrm{Cu}$ powders is $2 \mathrm{wt} \%$ or less. The dendritic $\mathrm{Ag} / \mathrm{Cu}$ powder particles used in this study have a few micron scale and high density; therefore, the alkanethiols adsorbed to the surface of a treated $\mathrm{Ag} / \mathrm{Cu}$ powder particle does not significant contribute to its weight. In practice, the TGA of $\mathrm{Ag} / \mathrm{Cu}$ powders evaluates their degree of oxidation at high temperatures rather than their organic matter content [12, 17, 29]. Accordingly, the degree of oxidation of the $\mathrm{Ag} / \mathrm{Cu}$ powders was examined by TGA under the same conditions but without nitrogen injection. As shown in Fig. 4, in the presence of oxygen, the weight of every sample increases with increasing temperature, indicating the oxidation of $\mathrm{Cu}$. A previous study featuring surface-untreated $\mathrm{Ag} / \mathrm{Cu}$ powders, found that the weight of the $\mathrm{Ag} / \mathrm{Cu}$ powder starts to increase once the temperature reaches $\sim 250^{\circ} \mathrm{C}$ and at $400^{\circ} \mathrm{C}$ the weight

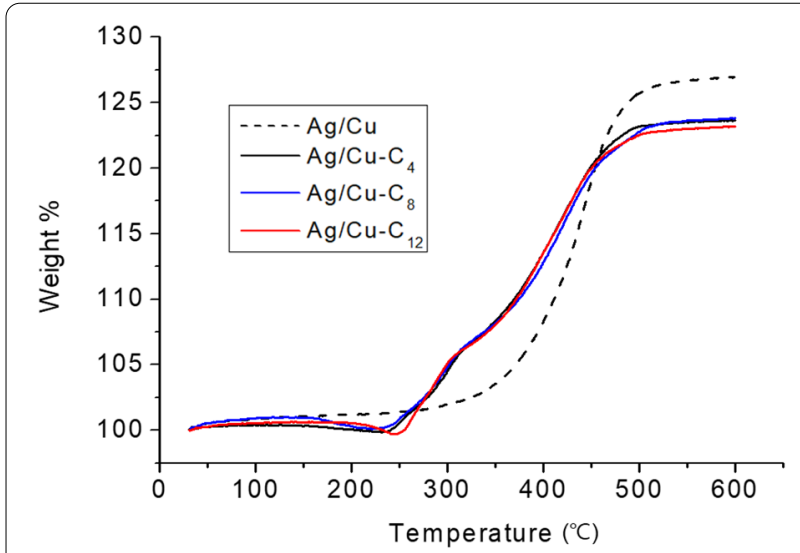

Fig. 4 TGA of untreated $\mathrm{Ag} / \mathrm{Cu}$ and alkanethiol-modified $\mathrm{Ag} / \mathrm{Cu}$ powders without nitrogen injection has increased by $\sim 9 \mathrm{wt} \%$ [26]. Another study reported that limited oxidation occurs from $175{ }^{\circ} \mathrm{C}$, and between 175 and $260{ }^{\circ} \mathrm{C}$ the weight increases by $\sim 1 \mathrm{wt} \%$. At temperatures exceeding $260^{\circ} \mathrm{C}$, oxidization occurs more rapidly and a weight increase of $\sim 7 \mathrm{wt} \%$ is recorded once the temperature reaches $400{ }^{\circ} \mathrm{C}$ [17]. In this study, the weight of the untreated $\mathrm{Ag} / \mathrm{Cu}$ powder increases very slowly from $\sim 170{ }^{\circ} \mathrm{C}$; however, the rate of weight increase accelerates from $\sim 260{ }^{\circ} \mathrm{C}$ and a weight increase of approximately $7.5 \mathrm{wt} \%$ is recorded once the temperature reaches $400{ }^{\circ} \mathrm{C}$. This result is consistent with the results reported by previous studies. In contrast, in the presence of oxygen, the weights of alkanethiol-modified $\mathrm{Ag} / \mathrm{Cu}$ powders decrease by $\sim 1 \mathrm{wt} \%$ up to $250{ }^{\circ} \mathrm{C}$ before increasing. It is considered that the initial slight decrease in weight is caused by the reduction of the $\mathrm{Ag} / \mathrm{Cu}$ surface upon the adsorption of alkanethiols; the subsequent weight gain observed for the alkanethiol-modified $\mathrm{Ag} / \mathrm{Cu}$ powders is attributed to the oxidation of the metal surfaces in the presence of oxygen. The difference in the weight gain behaviors of the respective alkanethiol-modified $\mathrm{Ag} / \mathrm{Cu}$ powders is negligible.

\subsection{Evaluation of electrically conductive films containing alkanethiol-modified $\mathrm{Ag} / \mathrm{Cu}$ powders}

After electrically conductive films were prepared by dispersing the various $\mathrm{Ag} / \mathrm{Cu}$ powders in epoxy resin, the degree of dispersion of the alkanethiol-modified Ag/ $\mathrm{Cu}$ powders was indirectly evaluated by measuring the surface roughness. While there are various ways of characterizing surface roughness, it is most commonly expressed in terms of the Ra and Rz. Ra is defined as the arithmetic mean of the absolute values of the ordinates of the measured profile relative to the midline along the measurement length. $\mathrm{Rz}$ is defined as the mean difference between the 5 lowest minima and the 5 highest maxima of the assessed surface profile [30]. In this study, the $\mathrm{Ra}$ and $\mathrm{Rz}$ values at five locations on each of the $7 \mathrm{~cm}$ $\times 1 \mathrm{~cm}$ films were measured; their mean and standard deviation are summarized in Table 2. The dispersion of the hydrophobic silica in the film containing untreated $\mathrm{Ag} / \mathrm{Cu}$ powder is poor, which is easily confirmed visually, and its surface roughness is relatively high based on

Table 2 Roughness of electrically conductive films containing untreated $\mathrm{Ag} / \mathrm{Cu}$ and alkanethiol-modified Ag/Cu powders

\begin{tabular}{llr}
\hline Sample & Ra $(\boldsymbol{\mu m})$ & $\mathbf{R z}(\boldsymbol{\mu m})$ \\
\hline $\mathrm{Ag} / \mathrm{Cu}$ & $2.043 \pm 0.15$ & $13.459 \pm 1.54$ \\
$\mathrm{Ag} / \mathrm{Cu}-\mathrm{C}_{4}$ & $0.719 \pm 0.17$ & $8.408 \pm 1.13$ \\
$\mathrm{Ag} / \mathrm{Cu}-\mathrm{C}_{8}$ & $0.760 \pm 0.13$ & $8.608 \pm 1.01$ \\
$\mathrm{Ag} / \mathrm{Cu}-\mathrm{C}_{12}$ & $0.631 \pm 0.10$ & $7.898 \pm 0.47$ \\
\hline
\end{tabular}


its $\mathrm{Ra}$ and $\mathrm{Rz}$ values of $\sim 2.403$ and $\sim 13.459 \mu \mathrm{m}$, respectively. The $\mathrm{Ra}$ and $\mathrm{Rz}$ values of the films containing alkanethiol-modified $\mathrm{Ag} / \mathrm{Cu}$ powders of $0.6-0.7$ and 7-8 $\mu \mathrm{m}$, respectively, are significantly lower than those of the film containing untreated $\mathrm{Ag} / \mathrm{Cu}$ powder.

This suggests that the alkanethiol modification of Ag/ $\mathrm{Cu}$ powders improves their compatibility with the epoxy resin to some extent. However, no significant correlation between the surface roughness of the film and the length of the alkyl chain of the alkanethiol-modified Ag/ $\mathrm{Cu}$ powders is evident.

We also investigated the thermal stability of the electrically conductive films. As established by the TGA of the untreated $\mathrm{Ag} / \mathrm{Cu}$ powder and previously reported studies $[17,29]$, the oxidation of $\mathrm{Ag} / \mathrm{Cu}$ powder commences at a temperature of approximately $170-175{ }^{\circ} \mathrm{C}$. Accordingly, the change in the linear resistance of each electrically conductive film over time was monitored in an oven at temperatures of 160 and $180{ }^{\circ} \mathrm{C}$, respectively; the results are plotted in Fig. 5.

The electrically conductive film containing untreated $\mathrm{Ag} / \mathrm{Cu}$ powder demonstrates much higher electrical resistance than those containing alkanethiol-modified $\mathrm{Ag} / \mathrm{Cu}$ powders. The high initial resistance is attributed to the surface oxidation of the $\mathrm{Au} / \mathrm{Cu}$ powder that occurred during the 1 -h curing process at $160{ }^{\circ} \mathrm{C}$ before thermal stability test. As shown in Fig. 5, the resistance of the film containing untreated $\mathrm{Ag} / \mathrm{Cu}$ powder increases rapidly at $160{ }^{\circ} \mathrm{C}$ over time, and even more rapidly at $180{ }^{\circ} \mathrm{C}$. In contrast, the resistance of electrically conductive films containing alkanethiol-modified $\mathrm{Ag} / \mathrm{Cu}$ powders remains relatively stable at $160{ }^{\circ} \mathrm{C}$, their resistance increases by less than $50 \%$ after $10 \mathrm{~h}$ of incubation at $160^{\circ} \mathrm{C}$. However, the resistance of the films increases more rapidly at $180^{\circ} \mathrm{C}$; the measurements had to be halted after $5 \mathrm{~h}$ owing the twisting of the films. In addition, while there is no significant difference in the resistance behaviors of the films containing alkanethiolmodified $\mathrm{Ag} / \mathrm{Cu}$ powders, their resistance increases in terms of alkyl-chain length in the order: $\mathrm{C}_{8}<\mathrm{C}_{12}<\mathrm{C}_{4}$. The above results show that the thermal stability of the $\mathrm{Ag} / \mathrm{Cu}$ powder is significantly improved by the adsorbed alkanethiols. Therefore, soldering heat resistance of the films shown in Fig. 6 were evaluated according to the method described in the experimental section that simulates soldering conditions.

The test prescribed involves processing each film at $260{ }^{\circ} \mathrm{C}$ for $10 \mathrm{~s}$ and then measuring the linear resistance at room temperature, the heat treatment and measurement process is repeated three times. The resistance of the film containing untreated $\mathrm{Ag} / \mathrm{Cu}$ powder is relatively high after the first heat treatment, while the resistance of the films containing alkanethiol-modified $\mathrm{Ag} / \mathrm{Cu}$ powders is relatively stable, indicating that the thermal stability of the films is improved by the modification of the $\mathrm{Ag} / \mathrm{Cu}$ powders with alkanethiols. The effect of the alkylchain length of the alkanethiol-modified $\mathrm{Ag} / \mathrm{Cu}$ powders is also evident, i.e., the film containing the $\mathrm{Ag} / \mathrm{Cu}$ powder modified with octanethiol $\left(\mathrm{Ag} / \mathrm{Cu}-\mathrm{C}_{8}\right)$ is the most stable film. In the case of the film containing butanethiolmodified $\mathrm{Ag} / \mathrm{Cu}$ powder $\left(\mathrm{Ag} / \mathrm{Cu}-\mathrm{C}_{4}\right)$, the increase in its resistance after each heat treatment is greater than the corresponding increase observed in the resistance of the film containing dodecanethiol-modified $\mathrm{Ag} / \mathrm{Cu}$ powder $\left(\mathrm{Ag} / \mathrm{Cu}-\mathrm{C}_{12}\right)$. These results are judged to indicate efficient thermal stability; although, the longer the alkyl chain

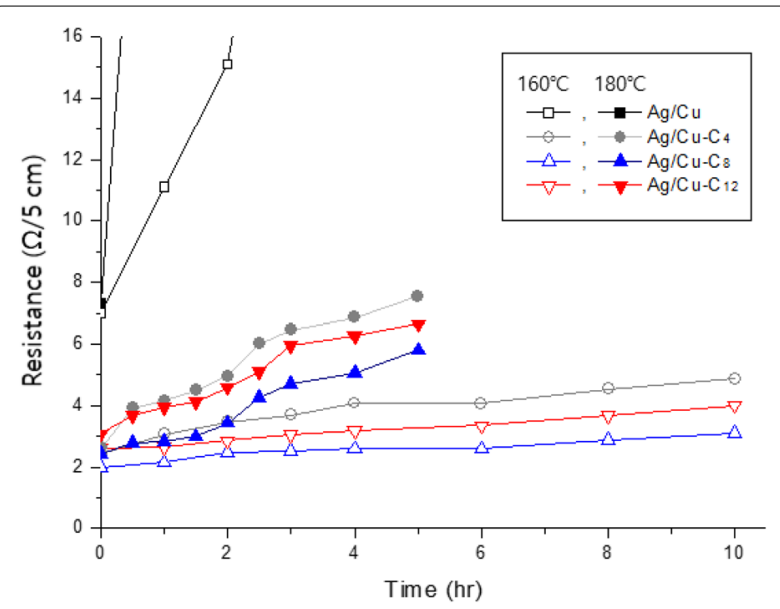

Fig. 5 Resistance of electrically conductive films containing untreated $\mathrm{Ag} / \mathrm{Cu}$ and alkanethiol-modified $\mathrm{Ag} / \mathrm{Cu}$ powders incubated at 160 and $180^{\circ} \mathrm{C}$, respectively

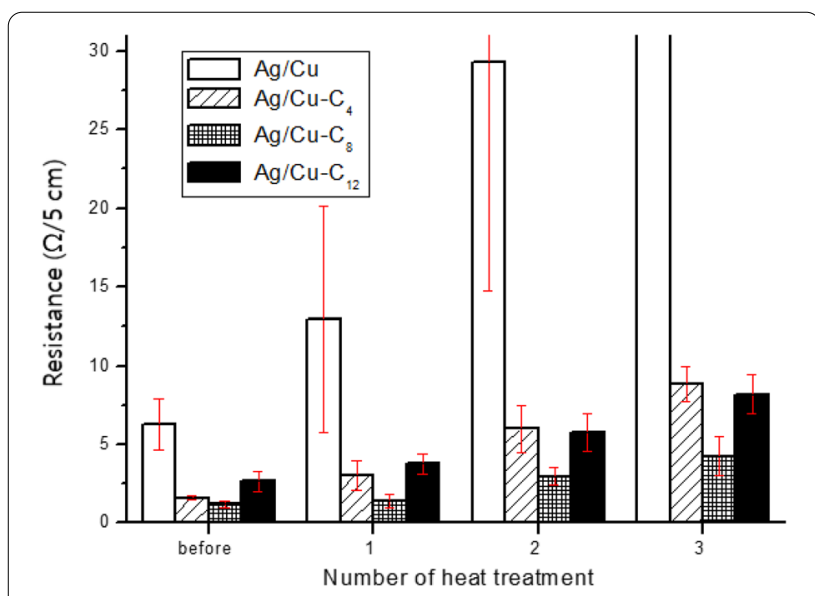

Fig. 6 Resistance of electrically conductive films containing untreated $\mathrm{Ag} / \mathrm{Cu}$ and alkanethiol-modified $\mathrm{Ag} / \mathrm{Cu}$ after successive heat treatments at $260^{\circ} \mathrm{C}$ 
of the alkanethiol, the lower the electrical properties of the alkanethiol-modified $\mathrm{Ag} / \mathrm{Cu}$ powder. In practice, the rate at which the resistance of the film increases (R3/R0), i.e., the linear resistance after three heat treatments (R3) divided by the original linear resistance (R0), is found to be $5.57,3.54$, and 3.08 for the $\mathrm{Ag} / \mathrm{Cu}-\mathrm{C}_{4}, \mathrm{Ag} / \mathrm{Cu}-\mathrm{C}_{8}$, and $\mathrm{Ag} / \mathrm{Cu}-\mathrm{C}_{12}$ films, respectively, indicating that the longer the alkyl chain, the smaller the increase in resistance induced by the heat treatment. In other words, the longer the alkyl chain of the alkanethiol-modified $\mathrm{Ag} / \mathrm{Cu}$ powder, the higher the resistance of the film due to the greater amount of organic matter surrounding the $\mathrm{Ag} /$ $\mathrm{Cu}$ powder particles; however, the longer the alkyl chain of the alkanethiol-modified $\mathrm{Ag} / \mathrm{Cu}$ powder, the lower its vulnerability to oxidation and the smaller the increase in the resistance of the film caused by heat treatment. These effects combine to produce the lowest resistance in the $\mathrm{Ag} / \mathrm{Cu}-\mathrm{C}_{8}$ film after three heat treatments.

\section{Conclusions}

In order to improve the thermal stability of dendritic $\mathrm{Ag} /$ $\mathrm{Cu}$ powders, the surfaces of the $\mathrm{Ag} / \mathrm{Cu}$ powders were modified with alkanethiols featuring alkyl chains of different lengths. These powders were used to fabricate electrically conductive films in combination with an epoxy resin. The thermal stability of the conductive films (at 160 and $180{ }^{\circ} \mathrm{C}$ ) was investigated and the films were also subjected to a thermal stability test(three successive heat treatments at $260{ }^{\circ} \mathrm{C}$ for $10 \mathrm{~s}$ each). The results confirm that the modification of $\mathrm{Ag} / \mathrm{Cu}$ powders with alkanethiols remarkably improve their thermal stability. The thermal stability of the films containing alkanethiolmodified $\mathrm{Ag} / \mathrm{Cu}$ powders does not vary significantly in terms of alkyl-chain length. The longer the alkyl-chain of the alkanethiol-modified $\mathrm{Ag} / \mathrm{Cu}$ powder, the higher the initial resistance of the associated electrically conductive film. However, the increase in the resistance of the films containing alkanethiol-modified $\mathrm{Ag} / \mathrm{Cu}$ powders due to heat treatment is relatively small. As a result, the best electrical characteristics are demonstrated by the film containing octanethiol-modified $\mathrm{Ag} / \mathrm{Cu}$ powder $\left(\mathrm{Ag} / \mathrm{Cu}-\mathrm{C}_{8}\right)$. The results of this study suggest that $\mathrm{Ag} / \mathrm{Cu}$ powders are promising fillers for electrically conductive adhesives.

\footnotetext{
Abbreviations

SEM-EDS: Scanning electron microscopy with energy dispersive spectroscopy; XPS: X-ray photoelectron spectroscopy; TGA: Thermogravimetric analysis; Ra: Arithmetic mean roughness; Rz: Ten-point mean roughness.
}

Acknowledgements

Not applicable.

\section{Authors' contributions}

THK and HK contributed equally to this work. All authors contributed to the writing of the manuscript, design of the figure sets, and analyses. All authors read and approved the final manuscript.

\section{Funding}

This research was supported by a grant from the Korea Technology and Information Promotion Agency for SMEs (TIPA) by the Ministry of SMEs and Startups (S2448979), the National Research Foundation of Korea (2019R1C1C1009427), and by Gachon University (GCU-2019-0819).

Availability of data and materials

Not applicable.

\section{Declarations}

\section{Competing interests}

The authors declare that they have no competing interests.

\section{Author details}

'Department of Chemistry, Gachon University, Seongnam-Si 13120, Republic of Korea. ${ }^{2}$ Department of Polymer Engineering, College of Engineering, University of Suwon, Suwon 18323, Republic of Korea. ${ }^{3}$ Mazal Co., Ltd, \#505, 506, Business Incubation Center, Kyunggi University, Suwon 16227, South Korea. ${ }^{4}$ Department of Chemical and Molecular Engineering, Hanyang University, Ansan-Si 15588, Republic of Korea. ${ }^{5}$ Center for Bionano Intelligence Education and Research, Hanyang University, Ansan-Si 15588, Republic of Korea.

Received: 23 March 2021 Accepted: 7 May 2021

Published online: 20 May 2021

\section{References}

1. B. Bridge, M.J. Folkes, B.R. Wood, Investigation into the DC conductivity of colloidally dispersed gold/polymer composites. J. Phys. D 23(7), 890-898 (1990)

2. C. Vericat, M.E. Vela, G. Benitez, P. Carro, R.C. Salvarezza, Self-assembled monolayers of thiols and dithiols on gold: new challenges for a wellknown system. Chem. Soc. Rev. 39(5), 1805-1834 (2010)

3. A.S. Cebrián, F. Klunker, M. Zogg, Simulation of the cure of paste adhesive by induction heating. J. Compos. Mater. 48(12), 1459-1474 (2013)

4. I. Novak, I. Krupa, Electro-conductive resins filled with graphite for casting applications. Eur. Polym. J. 40(7), 1417-1422 (2004)

5. W. Lin, X. Xi, C. Yu, Research of silver plating nano-graphite filled conductive adhesive. Synth. Met. 159(7-8), 619-624 (2009)

6. V. Brusic, M.A. Frisch, B.N. Eldridge, F.P. Novak, F.B. Kaufman, B.M. Rush, G.S. Frankel, Copper corrosion with and without inhibitors. J. Electrochem. Soc. 138(8), 2253-2259 (1991)

7. A.M. Fenelon, C.B. Breslin, An electrochemical study of the formation of benzotriazole surface films on copper, zinc and a copper zinc alloy. J. Appl. Electrochem. 31(5), 509-516 (2001)

8. E.M. Sherif, S.M. Park, Inhibition of copper corrosion in $3.0 \% \mathrm{NaCl}$ solution by N-Phenyl-1,4-phenylenediamine. J. Electrochem. Soc. 152(10), B428B433 (2005)

9. Y.S. Tan, M.P. Srinivasan, S.O. Pehkonen, S.Y.M. Chooi, Effects of ring substituents on the protective properties of self-assembled benzenethiols on copper. Corros. Sci. 48(4), 840-862 (2006)

10. M.M. Antonijevic, M.B. Petrovic, Copper corrosion inhibitors. A review. Int. J. Electrochem. Sci. 3(1), 1-28 (2008)

11. J.N. Keuler, L. Lorenzen, R.D. Sanderson, V. Prozesky, W.J. Przybylowicz, Characterization of electroless plated palladium-silver alloy membranes. Thin Solid Films 347(1), 91-98 (1999)

12. X.G. Cao, H.Y. Zhang, Preparation of silver-coated copper powder and its oxidation resistance research. Powder Technol. 226, 53-56 (2012)

13. N. Koto, J. Yunkawa, T. Moro, Process for the production of a silver coated copper powder and conductive coating composition. US Patent, 4652, 465 (1987) 
14. T. Hayashi, Production of silver-coated copper-based powders. US Patent, 5178, 909 (1993)

15. J. Li, X. Pan, S. You, S. Huang, Method for surface treating conductive copper powder with a treating agent and coupler. US Patent, 5372, 749 (1994)

16. S. Djokic, M. Dubois, R.H. Lepard, Process for the production of silver coated particles. US Patent, 5945, 158 (1999)

17. Y.S. Lin, S.S. Chiu, Electrical properties of conductive adhesives as affected by particle compositions, particle shapes, and oxidizing temperatures of copper powders in a polymer matrix. J. App. Polym. Sci. 93(5), 2045-2053 (2004)

18. Y.S. Lin, S.S. Chiu, Electrical properties of copper-filled electrically conductive adhesives and pressure dependent conduction behavior of copper particles. J. Adhes. Sci. Technol. 22(14), 1673-1697 (2008)

19. D.S. Jung, H.M. Lee, Y.C. Kang, S.B. Park, Air-stable silver-coated copper particles of sub-micrometer size. J. Colloid Interface Sci. 364(2), 574-581 (2011)

20. J. Zhao, D. Zhang, X. Zhang, Preparation and characterization of copper/ silver bimetallic nanowires with core-shell structure. Surf. Interface Anal. 47(4), 529-534 (2009)

21. Y.-S. Park, C.Y. An, P.K. Kannana, N. Seo, K. Zhuo, T.K. Yoo, C.-H. Chung, Fabrication of dendritic silver-coated copper powders by galvanic displacement reaction and their thermal stability against oxidation. Appl. Surf. Sci. 389(15), 865-873 (2016)

22. A. Pajor-Świerzy, Y. Farraj, A. Kamyshny, S. Magdassi, Air stable coppersilver core-shell submicron particles: Synthesis and conductive ink formulation, Colloids Surf. A Physicochem. Eng. Asp. 521 (20), 272-280 (2017)

23. H. Nishikawa, S. Mikami, K. Miyake, A. Aoki, T. Takemoto, Effects of Silver Coating Covered with Copper Filler on Electrical Resistivity of Electrically Conductive Adhesives. Mat. Trans. 51(10), 1785-1789 (2010)
24. R. Zhang, W. Lin, K. Lawrence, C.P. Wong, Highly reliable, low cost, isotropically conductive adhesives filled with Ag-coated Cu flakes for electronic packaging applications. Int. J. Adhes. Adhes. 30(6), 403-407 (2010)

25. J. Zhao, D. Zhang, Epoxy-based adhesives filled with flakes ag-coated copper as conductive fillers. Polym. Compos. 38(5), 846-851 (2015)

26. M.C. Biesinger, L.W.M. Lau, A.R. Gerson, R.S.C. Smart, Resolving surface chemical states in XPS analysis of first row transition metals, oxides and hydroxides: Sc, Ti, V, Cu and Zn. Appl. Surf. Sci. 257(3), 887-898 (2010)

27. Y. Wang, J. Im, J.W. Soares, D.M. Steeves, J.E. Whitten, Thiol adsorption on and reduction of copper oxide particles and surfaces. Langmuir 32(16), 3848-3857 (2016)

28. J. Joo, H.S. Kim, J.T. Kim, H.J. Yoo, J.R. Lee, I.W. Cheong, Synthesis and characterization of epoxy silane-modified silica/polyurethane-urea nanocomposite films. Korean Chem. Eng. Res. 50(2), 371-378 (2012)

29. Y.S. Lin, S.S. Chiu, Effects of oxidation and particle shape on critical volume fractions of silver coated copper powders in conductive adhesives for microelectronic applications. Polym. Eng. Sci. 44(11), 2075-2082 (2004)

30. T. Eliades, C. Gioka, G. Eliades, M. Makou, Enamel surface roughness following debonding using two resin grinding methods. Eur. J. Orthod. 26(3), 333-338 (2004)

\section{Publisher's Note}

Springer Nature remains neutral with regard to jurisdictional claims in published maps and institutional affiliations.

\section{Submit your manuscript to a SpringerOpen ${ }^{\circ}$ journal and benefit from:}

- Convenient online submission

- Rigorous peer review

- Open access: articles freely available online

- High visibility within the field

- Retaining the copyright to your article

Submit your next manuscript at $\boldsymbol{\nabla}$ springeropen.com 